gynaecologists. I have recently operated on a patient who had had this procedure carried out, only to find a normal but perhaps shortened appendix in its normal place. It was approximately 2 inches $(5 \mathrm{~cm})$ long with no mesenteric attachment. The mesoappendix, which had been left long, had in fact wrapped itself around the small bowel, causing intestinal obstruction.

I understand that this technique of inversion of the appendix is quite popular in certain areas and is gaining in popularity. It would seem to me there must be dangers associated with this procedure, not the least being the fact that the patient may still be able to get appendicitis, whether it is intraluminal, intramural, or simply shortened. I have a feeling that complications of this procedure may not be reported in the literature and I would be very grateful if any details of patients suffering from complications of this procedure oould be sent to me so that we can get a realistic viewpoint of the complication rate.-I am, etc.,

Southlands Hospital,
Shoreham-by-Sea, Sussex

GEORGE H. DICKSON

\section{Who is the Dental Anaesthetist of the Future?}

SIR,-Congratulations are due to Professor P. A. Bramley and his colleagues (4 May, p. 270) for their constructive attempt to initiate training of dental anaesthetists by apprenticeship. Students attending the short courses organized by the Society for the Advancement of Anaesthesia in Dentistry have always been advised to work at first under the supervision of an expert. The difficulty has been in finding sufficient teachers capable and willing to take an apprentice.

The adoption of an approved system of apprenticeship would necessitate the publication of an approved list of dental anaesthetists. This would be welcomed by all dentists wishing to make contact with an anaesthetist who is willing and able to work in their locality. At present this contact can be made only through hearsay or personal recommendation. Anaesthetists who allow their name and address to appear on such a list would be just as ethical as doctors on the obstetric list or consultants on the list for domiciliary consultations. We all seek and hope for a countrywide availability for every dental practitioner of an anaesthetist trained and experienced in modern methods for both conservative and surgical dentistry.

If it is impractical to bring the anaesthetist to the dentist, then bring the dentist and his patient to the anaesthetist at a centre fully equipped to deal with all eventualities. This system works well in several successful private practices and could be equally successful under an intelligent N.H.S. administration.-I am, etc.,

London $\mathbf{W} .4$

Donald BLATCHLEY

SIR,-The suggestion of Professor P. A. Bramley and others (4 May, p. 270) that dentists could by a scheme of "a half-day a week" instruction in dental anaesthesia be turned into qualified dental anaesthetists is simply nonsense.
Dental anaesthetics is one of the most difficult branches of the medical specialty of anaesthesia; it is no different from and no less dangerous than anaesthesia for a cholecystectomy. It is mandatory that all anaesthetics be given by medically qualified and fully trained anaesthetists. No patient should be given any anaesthetic without a full physical examination, for example.

When are dentists going to realize that anaesthetics is a medical specialty? If one of their own family ever required a dental anaesthetic I know who would be asked to give it-a fully qualified anaesthetist.-I am, etc.

Lyneham, wilts

D. HOGG

\section{Smoking in Pregnancy}

SIR,-I was one of the doctors who wrote to Mr. A. C. L. Mackie, Director General of the Health Education Council (6 April, p. 55) to criticize the leaflet showing a naked, pregnant, smoking woman. I made the point that the photograph was an example of very bad taste. Mr. Mackie does not appear to defend it from that point of view. I also said that education should be directed to an improvement of all aspects of life, that health was important but there were other values to be considered, and that it was not right to make use of material which would tend to bring the pregnant woman into contempt, even for the most admirable ends.

I do not smoke and am a man and therefore not pregnant. Because of this $\mathrm{Mr}$. Mackie asserts that what I and others like me think about this matters very little. By the same token, of course, his own opinion is of no importance. I do not agree with him. What he and I and all other doctors and others concerned with health education think does matter.-I am, etc.,

South Tyneside Area Health Authority,

R. P. RYAN

\section{Jaundice after Halothane}

SIR,-With reference to the article by $\mathrm{Dr}$. W. H. W. Inman and Professor W. W. Mushin (5 January, p. 5) on the incidence of jaundice following repeated exposure to halothane it is worth noting that nearly all writers stress the wide use of halothane$80 \%$ of all general anaesthetics according to Mushin et al. 1 Often the problem of substituting an alternative agent as "safe and effective" as halothane is stressed, seeming to imply that it is mandatory to add a volatile agent to nitrous oxide and oxygen. A general reduction in the use of halothane would lessen the chances of susceptible individuals being rechallenged by it, as well as providing experience in alternative techniques now obviously lacking.

A sizable minority of anaesthetists use a premedication, intravenous induction, nitrous oxide, oxygen, and relaxant sequence with or without analgesic supplement and no additional inhalational agent whatsoever for $90 \%$ of their anaesthetics. Admittedly, more care is required to avoid the possibility of awareness, but by what criteria do the ease and convenience of using a blanket "almost safe" anaesthetic take preoedence over the exercise of proper skill and judgement by a specialist trained for that very purpose?-I am, etc.,

North Adelaide,

South Australia

Mushin, W. W., Rosen, M., and Jones, E. V., British Medical fournal, 1971, 3, 18.

\section{Diagnostic Problems in Cervical Cancer}

SIR,--In your leading article (16 March, p. 471) on this subject you drew atention to the high proportion of cases in which the panel of gynaecological pathologists set up by the Royal College of Obstetricians and Gynaecologists disagreed with the diagnosis made by the submitting pathologist; and you went on to assert that "this evidence demands a critical review of diagnostic criteria for cervical lesions in every gynaecological department."

In fact in 1966 and again in 1969 my colleagues and I set out ${ }^{2}$ to establish clearly defined morphological categories to which the various histological changes can be readily and reproducibly assigned. We did so hoping that this would lead to uniformity in reporting which would facilitate the critical review that your leading article demands. - I am, etc.

\section{Magnus HaINES}

Department of Pathology,

Chelsea Hospital for Women

1 Govan, A. D. T., et al., fournal of Obstetrics and Gynaecology of the British Commonwealth, 1966, 73, 883. T et al., fournal of Clinical Pathology, 1969, 22, 383 .
Povan, A. D. T.

\section{Amitriptyline and Imipramine Poisoning in Children}

SIR,-With reference to the article by Drs. K. M. Goel and R. A. Shanks (16 February, p. 261), in the renal unit of our department, which is mainly devoted to the dialysis treatment of infants and children, we have treated two cases of severe imipramine poisoning by haemodialysis. ${ }^{2}$ The patients (aged 26 months and 4 years), who had taken imipramine in dosages of $23 \mathrm{mg} / \mathrm{kg}$ and $20 \mathrm{mg} / \mathrm{kg}$ respectively, were deeply comatose, with convulsions and electrocardiographic abnormalities on admission. Haemo dialysis was started promptly and the children regained consciousness after as little as 4-5 hours. The dosages in these cases must be regarded as highly hazardous as the minimum lethal dose for infants and children has been stated ${ }^{3}$ to be only $8 \mathrm{mg} / \mathrm{kg}$ in contrast to $30 \mathrm{mg} / \mathrm{kg}$ for adults. The danger to children of imipramine in doses which would not be lethal to adults is also emphasized by the fact that two of the children reported by Drs. Goel and Shanks died after the ingestion of $15 \mathrm{mg} / \mathrm{kg}$.

Successful haemodialysis treatment of an adult after imipramine poisoning has previously been reported by Harthorne et al. and that of a child by Bauditz and Barthelheimer. ${ }^{5}$ Compared with the conservative management of poisoning by tricyclic antidepressants the duration of coma seems to be favourably shortened by haemodialysis. The amount of imipramine recovered in the dialysate is not so small as has been supposed. Clearance studies are at present being performed by our group and will be 